Available online on 15.08 .2020 at http://jddtonline.info
Open Access to Pharmaceutical and Medical Research
unrestricted non-commercial use, provided the original work is properly cited

Open $\odot$ Access

\title{
Amoxicillin Induced Steven Johnson's Syndrome: A Case Report
}

\author{
Mahendra Kumar R ${ }^{1 *}$, Sanatkumar Nyamagoud ${ }^{1}$, Krishna Deshpande ${ }^{2}$, Ankitha Kotian ${ }^{3}$ \\ 1* Pharm D., Intern, Acharya \& BM Reddy College of Pharmacy, Bengaluru, Karnataka, India-560090 \\ ${ }^{1}$ Pharm D., Assistant Professor, Department of Pharmacy Practice, KLE College of Pharmacy, Hubli, Karnataka, India-580031 \\ 2 Pharm D., Intern, HSK College of Pharmacy, Bagalkot, Karnataka, India - 587101
}

3 Pharm D., Shree Devi College of Pharmacy, Mangalore, Karnataka, India -575003

\begin{abstract}
Stevens-Johnson syndrome (SJS) is a very rare, potentially fatal skin reaction that is typically the result of reaction to the drug. In particular, SJS is characterized by extensive skin and mucous membrane lesions (i.e. mouth, nose, esophagus, anus, and genitalia), epidermis detachment, and acute skin blisters. In $95 \%$ of case reports, drugs were found to be an important cause for the development of SJS. This story is a case of A 42 year old male hospitalized with rashes all over the body and fever, after oral consumption of Amoxicillin drug for sore throat. This case study discusses the possibility that serious hypersensitivity reactions with Amoxicillin can rarely occur and can be extremely harmful and lifethreatening Menacing.
\end{abstract}

Keywords: Toxic Epidermal Necrolysis, Stevens Johnson Syndrome, Adverse drug reaction, Nikolsky’s sign

Article Info: Received 10 June 2020; Review Completed 19 July 2020; Accepted 26 July 2020; Available online 15 August 2020

Cite this article as:

Mahendra Kumar R, Nyamagoud S, Deshpande K, Kotian A, Amoxicillin Induced Steven Johnson's Syndrome: A Case

Report, Journal of Drug Delivery and Therapeutics. 2020; 10(4-s):220-222 http://dx.doi.org/10.22270/jddt.v10i4-s.4205

*Address for Correspondence:

Mr. Mahendra Kumar R, Doctor of Pharmacy (Pharm.D) Intern, Acharya \& BM Reddy college of Pharmacy, Acharya Dr. Sarvepalli Radhakrishnan Road, Near Hesaraghatta Main Road, Soldevanahalli, Chikkabanavara Post, Bengaluru, Karnataka, India-560 050.

\section{INTRODUCTION:}

Adverse drug reactions (ADR) accounts for 6 percent of total hospital admissions, increases the economic burden on the healthcare system, leads to market withdrawal and death of drugs. Cutaneous drug reactions, mostly Stevens Johnson Syndrome (SJS) and Toxic Epidermal Necrolysis (TEN), are rare but potentially fatal reactions that threaten the life of the patient 1 .

Stevens-Johnson syndrome (SJS) is a severe, life-threatening disease normally associated with the use of medications rather than other etiological conditions. It is a severe form of exfoliative dermatitis, characterised by extensive epidermal erythema and blistering that eventually result in epidermal necrosis and detachment. It is a mucocutaneous cellmediated hypersensitivity reactions. This is usually a reaction to medicine that starts with symptoms like fever, accompanied by a painful rash that spreads and blisters. For some days the top layer of infected skin falls, sheds and starts to recover.

Historically, two American physicians named Stevens and Johnson described SJS for the first time in 1922. They described an acute mucocutaneous syndrome in two young boys with severe purulent conjunctivitis, severe stomatitis with extensive mucosal necrosis 2 . The incidence of SJS has been reported to be 0.05 to 2 million persons per population per year. Mortality reported ranges from 3 to 10 per cent 3 . SJS is seen quite often in children vulnerable to viral infection, however Mortality is higher among older people 4 .

Sulphonamides, non-steroidal anti-inflammatory medications, antifungal imidazole, cephalosporins, anticonvulsants, allopurinol, wide spectrum bactericidal agents and HAART protocol are the most common medicines that induce SJS. Fluoroquinolones will seldom induce severe reactions to the cutaneous medications 3,4 . Here, we report a case of SJS-induced by Amoxicillin.

\section{CASE REPORT:}

A 42 Year old male presents with the complaints of fever, itchy skin eruptions all over the body for 4 days. He gave a history of sore throat for which he was administered with combination drug of Amoxicillin and clavulanic acid. The eruptions were seen after taking two doses.

After three days, patient developed unilateral painful skin lesions which were unruptured and filled with fluid. These 
lesions first appeared over the left fore arm and then gradually progressed to all over the body. The eruptions were hyperpigmented, target like and round lesions. The eruptions were $3-5 \mathrm{~cm}$ in diameter and present throughout the body and more concentrated on arms, palms, face and abdomen.
Patient was ill-looking, conscious, oriented with all his vitals in normal range. On examination, erosive vesicular lesions were present on tongue, lips, eyes and genitals. Which were associated with purulent discharge. Nikolsky's sign was positive. His laboratory investigation data on admission were as per table 1 .

Table 1: Laboratory data of the patient on the day of admission

\begin{tabular}{|l|l|l|}
\hline Parameter & Observed Value & Reference value \\
\hline Haemoglobin & $11.6 \mathrm{~g} / \mathrm{dl}$ & $11-14 \mathrm{~g} / \mathrm{dl}$ \\
\hline Red cells & $4.9 \mathrm{~m} / \mathrm{mcL}$ & $4.7-6.2 \mathrm{~m} / \mathrm{mcL}$ \\
\hline White blood cells & $11,000 \mathrm{c} / \mathrm{mcL}$ & $4500-10800 \mathrm{c} / \mathrm{mcL}$ \\
\hline Platelets & $6,70,000 / \mathrm{mm}^{3}$ & $150,00-450,00 / \mathrm{mm}^{3}$ \\
\hline Neutrophils & $83 \%$ & $40-75 \%$ \\
\hline ESR & $50 \mathrm{~mm}$ per $1^{\text {st }}$ hour & $1-15 \mathrm{~mm}$ per $1^{\text {st }}$ hour \\
\hline C-Reactive Protein & $26 \mathrm{mg} / \mathrm{dl}$ & $0.5-10 \mathrm{mg} / \mathrm{dl}$ \\
\hline Direct bilirubin & $3.82 \mathrm{mg} / \mathrm{dl}$ & $0-0.3 \mathrm{mg} / \mathrm{dl}$ \\
\hline Indirect bilirubin & $0.9 \mathrm{mg} / \mathrm{dl}$ & $<0.8 \mathrm{mg} / \mathrm{dl}$ \\
\hline Total bilirubin & $3.05 \mathrm{mg} / \mathrm{dl}$ & $0.3-1.0 \mathrm{mg} / \mathrm{dl}$ \\
\hline AST & $34 \mathrm{IU} / \mathrm{L}$ & $0-38 \mathrm{IU} / \mathrm{L}$ \\
\hline ALT & $37 \mathrm{IU} / \mathrm{L}$ & $0-41 \mathrm{IU} / \mathrm{L}$ \\
\hline GGT & $28 \mathrm{IU} / \mathrm{L}$ & $5-36 \mathrm{IU} / \mathrm{L}$ \\
\hline Serum creatinine & $0.8 \mathrm{mg} / \mathrm{dl}$ & $0.5-1.2 \mathrm{mg} / \mathrm{dl}$ \\
\hline
\end{tabular}

Viral and bacterial infection tests including for cytomegalo virus(CMV), mycoplasma pneumonia and Epstein barr virus (EBV) was negative. Skin biopsy revealed dermal inflammation confirming the biopsy was compatible with SJS.

Based on the clinical findings, laboratory data and skin biopsy patient was diagnosed with Amoxicillin induced steven-johnson's syndrome. On causality assessment using Naranjo's algorithm, association was probable for Amoxicillin.

The patient was managed aggressively with parenteral antibiotics, antihistamines, steroids and nutritional supplements. Patient recovered after rigorous treatment for 20 days. He was subsequently discharged well, after 3 weeks of rehabilitation.

\section{DISCUSSION:}

SJS is severe, life-threatening skin disorders under which the epidermis is separated from the dermis by cell death. This condition is known to be a complex of hypertensivity affecting the skin and mucous membranes. The exact etiology and diagnosis is not well known at this time.

Stevens-Johnson syndrome is an immune hypersensitivity complex that typically involves the skin and mucus membrane. SJS is minor form of toxic epidermal necrolysis (TEN). Clinical features include inflammation, blistering of mouth and eyes, and it attacks the deepest layer of the skin and mucous membrane.

SJS is thought to arise from a disorder of immune system. Genetic factors may play a role in SJS. Medications appear to be the most common cause of Stevens-Johnson syndrome and have been implicated in as many of $60 \%$ of cases studied. Incidence ranges from 1.2 to 6 cases per million per year 5 . The commonly associated drugs are antimicrobials (sulfonamide and other nonsulfonamide antibiotics such as aminopenicillins, cephalosporins, and quinolones), anticonvulsants (carbamazepine, phenytoin, phenobarbitone, and valproic acid), NSAIDs of the oxicam type, and allopurinol. 6-8

The antibiotics of penicillin may cause skin hypersensitivity reactions such as rash and erythema. Patel et al.[9] reported that penicillin is one of the antimicrobials that sometimes triggers serious adverse cutaneous drug reactions (CADRs) in the Indian population. To date, few cases of SIS / TEN induced with Amoxicillin have been reported $[8,10]$. Usually these adverse events are minimized by early removal of the suspected offending agent (Amoxicillin, in this case).

Combination therapy with Amoxicillin and clavulanic acid was identified as the causative agent because of the temporal relationship between the combination administration and the onset of eruptions. Several other earlier reports have also associated Amoxicillin and clavulanic acid to Stevens-Johnson syndrome.

While mild variants of erythema multiforme majus can cure in two to three weeks, it can take two to three months to heal from Stevens-Johnson syndrome, based on the amount of organs involved and disease intensity. ${ }^{11}$

\section{CONCLUSION:}

A causal association exists between the adverse effect (AE) and Amoxicillin. A frequent use of Amoxicillin and 
subsequent ADR's cannot be avoided in developing countries such as India, where infectious diseases are widely prevalent. This case report describes the risk of serious hypersensitivity reactions with Amoxicillin and clavulanic acid, which can be dangerous and life-threatening. Clinicians and clinical pharmacists also need to be more vigilant when administering this drug. Appropriate drug therapy and timely reporting of ADRs is therefore necessary to prevent non-compliance with treatment with subsequent clinical failure and increased resistance to antimicrobials.

\section{CONFLICTS OF INTEREST:}

The author declares that there is no conflict of interest to disclose.

\section{REFERENCES:}

1. Lihite RJ, et al. A study on drug induced SJS, TEN and SJS-TEN overlap. J Young Pharm. 2016; 8(2):149-53.

2. Bastuji-Garin S, Rzany B, Stern RS, Shear NH, Naldi L, Roujeau JC. Clinical classification of cases of toxic epidermal necrolysis, StevensJohnson syndrome, and erythema multiforme. Arch Dermatol. 1993; 129:92-6

3. Garcia-Doval I, LeCleach L, Bocquet H, Otero XL, Roujeau JC. Toxic epidermal necrolysis and Stevens-Johnson syndrome: Does early withdrawal of causative drugs decrease the risk of death? Arch Dermatol. 2000; 136:323-7
4. Patel PP, Gandhi AM, Desai CK, Desai MK, Dikshit RK. An analysis of drug induced Stevens-Johnson syndrome. Indian J Med Res 2012; 136(6):1051-3.

5. Wolkenstein P, Revuz J. Drug-induced severe skin reactions. Incidence, management and prevention. Drug Saf. 1995 Jul; 13(1):56-68

6 Roujeau J-C, Kelly JP, Naldi L, et al. Medication use and the risk of Stevens-Johnson syndrome or toxic epidermal necrolysis. N Engl J Med. 1995 Dec 14; 333(24):1600-7.

7. Sanmarkan AD, Sori T, Thappa DM, Jaisankar TJ. Retrospective analysis of Stevens-Johnson syndrome and toxic epidermal necrolysis over a period of 10 years. Indian J Dermatol 2011; 56(1):25-9.

8. Patil JR, Mothghare VM, Deshmukh VS, Jaykare SC, Pise HN. Penicillin-Induced Stevens-Johnson Syndrome: A Case Report. Indian J of Clinical Practice 2013; 24(7):626-7.

9. Patel TK, Barvaliya MJ, Sharma D, Tripathi C. A systematic review of the drug-induced Stevens Johnson syndrome and toxic epidermal necrolysis in Indian population. Indian J Dermatol Venereol Leprol 2013; 79(3):389-98.

10. Roujeau JC, Kelly JP, Naldi L, Rzany B, Stern RS, Anderson T, et al. Medication use and the risk of Stevens-Johnson syndrome or toxic epidermal necrolysis. N Engl J Med 1995; 333(24):1600-7.

11. Habif TP. Clinical Dermatology. 3rd ed. St Louis: MosbyYearBook; 1996. P 570-2. 